\title{
The Influence of a Glide Path on the Lifespan of WaveOne Reciprocating Files
}

\author{
Emilia Karova*, Snezhanka Topalova-Pirinska \\ Department of Conservative Dentistry, Faculty of Dental Medicine, Medical University, Sofia, Bulgaria \\ *Corresponding author: karova_e@yahoo.com
}

Received April 18, 2014; Revised May 23, 2014; Accepted May 23, 2014

\begin{abstract}
Background: Nickel-titanium instrument separation is a serious concern in endodontic therapy. A significant reduction of rotary instrument separation could be obtained when use of rotary file is anticipated by an initial manual preflaring and glide path. Normally this procedure is carried out by stainless steel hand files but new rotary nickel-titanium instruments (PathFiles) for mechanical glide path has been recently introduced. Methodology/Principal Findings: Canal preparation was performed on 100 Endo-Training Block simulators divided in two equal groups, depending on the used technique (with and without a glide path). Average lifespan and cumulative survival at the time of WaveOne (Dentsply Maillefer) files before and after the creation of a glide path with PathFiles (Dentsply Maillefer) were tested. Following the instructions of the producer all the files were operated using The WaveOne ${ }^{\mathrm{TM}}$ Endodontic system (Dentsply Maillefer). All WaveOne files worked till fracture occurred. During mechanical instrumentation each file was coated with Glyde ${ }^{\mathrm{TM}}$ (Dentsply Maillefer) to act as a lubricant, and copious irrigation with $5.25 \% \mathrm{NaOCl}$ was carried out. Eight WaveOne reciprocating files were used in canals' preparation and six of them broke: 4 files before the creation of a glide path and 2 after the initial enlargement of the canals with PathFile system. The average lifespan of one WaveOne file without a creation of a glide path was $10.25 \pm 2.50$ canals and after a creation of a glide path $-17.50 \pm 2.12$ canals. The difference was statistically significant $(\mathrm{p}<0.05)$. The instruments used after a glide path was created presented a significantly longer survival at the time $(p<0.05)$. Conclusions: Within the limits of this study, NiTi rotary Path Files appear to be suitable instruments for safe and easy creation of the glide path before use of WaveOne reciprocating files. The initial enlargement of the canals increases significantly the average lifespan and the survival rate of WaveOne files.
\end{abstract}

Keywords: nickel-titanium instruments, WaveOne, PathFiles, glide path, lifespan, cummulative survival

Cite This Article: Emilia Karova, and Snezhanka Topalova-Pirinska, "The Influence of a Glide Path on the Lifespan of WaveOne Reciprocating Files.” International Journal of Dental Sciences and Research, vol. 2, no. 3 (2014): 59-62. doi: 10.12691/ijdsr-2-3-3.

\section{Introduction}

The endodontic treatment outcome depends on root canal cleaning and shaping. The introduction of nickeltitanium rotary files has changed radically the root canal instrumentation techniques and the prognosis of endodontic complex cases. It is clearly demonstrated in many "in vitro" $[7,9,23,24,25,31,36]$ and "in vivo" $[17,26,29]$ studies that they are superior to stainless-steel files, especially during enlargement of the apical third of severely curved canals. At the same time, they had to be used with caution, because of the high risk of unexpected intracanal separation $[29,30]$.

The usage of NiTi instruments in curved canals is one of the most important reasons for their fractures [18]. These separations are caused by torsional $[1,5,6,39]$ and fatigue stresses $[4,5,16]$. The majority of torsional separations occurs when the tip of the instrument is engaged into the canal wall while the handpiece is still rotating $[1,4,6,16]$. Low torque motors and reduced axial pressure are ways to avoid the "taper lock" of the instruments with lower taper and/or diameter of the tip $[4,16]$. Repeated subthreshold loads, especially in the point of maximum flexure, result in metal fatigue and fracture $[21,22]$. In this case, the instrument stays loose into the canal space and rotates freely, without binding to the canal wall.

Manual preflaring and creation of a glide path before using nickel-titanium rotary instrumentation increases the canal diameter and thus reduces the risk of fracture $[2,14,19,33]$. Stainless steel hand files can be used for this procedure, though rotary nickel-titanium instruments are preferred lately, especially in the process of shaping of curved and/or calcified canals. An example of such system is the PathFiles (Dentsply Maillefer, Ballaigues, Switzerland), which consists of three instruments with square cross section, 21-25-31 mm length, 0.02 taper and size of the tip ISO 13, 16 and 19. According to the manufacturer the first PathFile can be used immediately after the root canal has been scout to full working length with a \#10 hand K-file.

The reciprocating way of motion may also decrease the impact of cyclic fatigue on nickel-titanium rotary instrument life $[13,34,40]$. The new WaveOne NiTi 
single-file system, manufactured with M-Wire NiTi alloy (Dentsply Tulsa Dental, Tulsa, OK), has been introduced by Dentsply Maillefer (Ballagues, Switzerland) and is designed to be used with a reciprocating motion motor. The reciprocating motion has different angles of rotation $170^{\circ}$ counterclockwise and then $50^{\circ}$ clockwise at a speed of $350 \mathrm{rpm}$. The system consists of 3 single-use files: small (ISO 21 tip and 6\% taper) for small canals, primary (ISO 25 tip and 8\% taper) for the majority of canals, and large (ISO 40 tip and 8\% taper) for large canals.

The aim of the present study was to examine the lifespan of one nickel-titanium WaveOne reciprocating file used for the instrumentation of artificial curved canals before and after the creation of a glide path.

\section{Materials and Methods}

Canal preparation was performed on 100 Endo-Training Block simulators (Dentsply Maillefer) divided in two equal groups, depending on the technique used. The canals had a 0.02 taper, an apical diameter of 0.15 , a 65 degree curvature and a $7.5 \mathrm{~mm}$ curvature radius.

Average lifespan and cumulative survival at the time of WaveOne (Dentsply Maillefer) files before and after the creation of a glide path with PathFiles (Dentsply Maillefer) were tested. Following the instructions of the producer all the files were operated using The WaveOne ${ }^{\mathrm{TM}}$ Endodontic system (Dentsply Maillefer), which is pre-programmed with settings for the WaveOne reciprocating file system. The amount of pressure applied to the file was the pressure that could be applied to a sharp \#2 pencil without breaking the lead. The files were never forced into the canal. In the first group the canals were scouted initially with a \#10 hand K-file to full working length and then were shaped with the small (ISO 21 tip and 6\% taper) WaveOne file. In the second group after scouting the canals with a \#10 hand K-file to full working length, a glide path was created using the PathFile system. The preparation was finished with the small (ISO 21 tip and 6\% taper) WaveOne file. All WaveOne files worked till fracture occurred.

During mechanical instrumentation each file was coated with Glyde $^{\mathrm{TM}}$ (Dentsply Maillefer) to act as a lubricant, and copious irrigation with 5.25\% $\mathrm{NaOCl}$ was carried out.

The instrumentation of all canals was performed by a single operator.

\section{Results}

\begin{tabular}{|c|c|c|c|}
\hline $\begin{array}{c}\text { File } \\
\text { № }\end{array}$ & $\begin{array}{l}\text { Preparation } \\
\text { technique }\end{array}$ & $\begin{array}{l}\text { Number of uses, } \\
\text { including the separation }\end{array}$ & $\begin{array}{c}\text { Number of } \\
\text { successfully treated } \\
\text { canals }\end{array}$ \\
\hline & WaveOne & & \\
\hline 1 & & 8 & 7 \\
\hline 2 & & 11 & 10 \\
\hline 3 & & 14 & 13 \\
\hline 4 & & 12 & 11 \\
\hline \multirow[t]{2}{*}{5} & & $*$ & 5 \\
\hline & $\begin{array}{c}\text { WaveOne+P } \\
\text { athFile }\end{array}$ & & \\
\hline 6 & & 17 & 16 \\
\hline 7 & & 20 & 19 \\
\hline 8 & & * & 13 \\
\hline
\end{tabular}

Average Lifespan of WaveOne Reciprocating Files

Eight WaveOne reciprocating files were used in canals' preparation and six of them broke: 4 files before the creation of a glide path and 2 after the initial enlargement of the artificial canals with PathFile system. The longest lifespan of a single file from the first group was 13 canals and from the second group - 19 canals. The shortest lifespan was measured in the first group and was 7 canals. (Table 1).

The average lifespan of one WaveOne file without $\boldsymbol{a}$ creation of a glide path was $10.25 \pm 2.50$ canals and after a creation of a glide path - 17.50 \pm 2.12 canals. The difference was statistically significant $(\mathrm{p}<0.05)$ (t-test). (Table 2).

Table 2. The Average Lifespan of WaveOne Reciprocating Files

\begin{tabular}{|c|c|c|c|c|}
\hline \multirow{2}{*}{\multicolumn{2}{|c|}{ Wave One $(n=4)$}} & \multirow{2}{*}{\multicolumn{2}{|c|}{ Wave One+Path File $(n=2)$}} & \multirow{3}{*}{$\mathrm{P}$} \\
\hline & & & & \\
\hline Mean & SD & Mean & SD & \\
\hline 10.25 & 2.5 & 17.50 & 2.12 & \\
\hline
\end{tabular}

Cumulative Survival at the Time of WaveOne Reciprocating Files

The cumulative proportion surviving at the time for WaveOne files, without the creation of a glide path, was $75 \%$ at the instrumentation of the $8^{\text {th }}$ canal with one and the same file, $50 \%$ of the $11^{\text {th }}$ one and $25 \%$ at the shaping of the twelve one.

The cumulative proportion surviving at the time for WaveOne files, after the creation of a glide path, was 50\% at the instrumentation of the $17^{\text {th }}$ canal and all files were separated at the instrumentation of the $20^{\text {th }}$ canal.

At the instrumentation of the $14^{\text {th }}$ canal, after the creation of a glide path, all WaveOne Files were intact (100\% survival), while all of them from the first group (without a glide path) were broken.

Figure 1 shows the survival curves of the instruments with and without a creation of a glide path using the logrank test. The instruments used after a glide path was created presented a significantly longer survival $(p<0.05)$. (Figure 1).

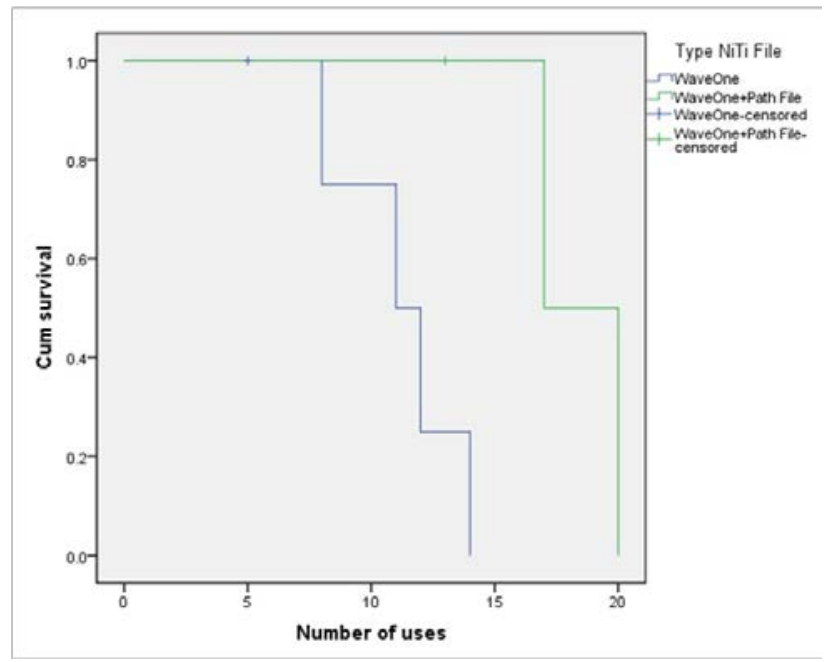

Figure 1. Cumulative Proportion Surviving at the Time of WaveOne Reciprocating Files

\section{Discussion}

Rotary nickel-titanium instruments allow the instrumentation of curved canals more predictably well 
centered, with lesser risks of transportation, ledging, and perforations than stainless-steel instruments [28]. Nevertheless, despite all the aforementioned benefits, there is a higher risk of instrument separation with rotary NiTi instruments, specifically during the instrumentation of curved canals $[10,27,40]$. It was shown in in vitro investigations that a stronger curvature and a smaller radius of the root canal increase the risk of rotary instrument fracture $[11,18,41]$. In a curvature, fracture occurs because of the repeated tensile and compressive stresses that lead to cyclic flexural fatigue by work hardening within the metal and the initiation of cracks from the outer surface of the instrument [12]. That is why, most clinical guidelines and manufacturers' recommendations for instrumentation with rotary NiTi instruments insist on the reduction of canal curvature by creating straight-line access and by reduction of the interference of the instrument with canal walls. However, clinically, a perfect straight-line access is not always possible, so initial enlargement of the canal should be performed. Fine hand instruments are usually used for the creation of a smooth glide path which will make subsequent use of the larger rotary NiTi instruments safer and more effective [8,20]. Negotiation and glide path preparation are the initial phases of chemomechanical procedures and can be regarded as crucial steps for assessment of the root canal anatomy and establishment of unimpeded access to the apical part of the canal [15]. Occurrence of canal modifications and aberrations seems to be significantly reduced when previous glide path is performed [2,3,33].

We used in our investigation standardized artificial canals, which according to Yao et al. [37] minimize the influence of other variables. In the present study, all instrument breakage occurred in the apical portion of the canal, a few millimeters from the tip of the file. Our findings are in agreement with the observations of Tygesen et al. [32] and Varela et al. [33] and can be explained with the fact that instruments break at the point of maximum flexure within the canal (e.g. the curvature), precisely where the stress is greatest. The broken files showed no visible defects, other than the breakage itself and did not seem to bind within the canals. Following the results from the work of Sattapan et al. [21], the lack of signs of deterioration above the fracture point, indicates that files broke because of fatigue rather than torsional stress.

The results from our study confirm the findings from other investigations, concerning the role of preliminary preflaring and creation of a glide path for safer use of rotary NiTi instrumentation [2,33]. The comparison between the two examined groups showed a statistically significant difference. The average lifespan of WaveOne file from the first group (without a creation of a glide path) increased from $10.25 \pm 2.50$ canals to $17.50 \pm 2.12$ canals (with created glide path) in the second group. The number of broken files in the second group decreased twice and it is worth mentioning how great the number of successfully treated canals with one file was - 16 and 19. The longest lifespan for the files from the first group was 13 canals and the mean number successfully treated canals was 10 canals, the same as the results found out by Varela-Patino et al. [35]. It can be hypothesized that the use of small size hand K-file followed by more flexible and less tapered rotary NiTi PathFiles could provide advantages in the form of the canal, making the subsequent instrumentation with WaveOne single-file technique safer and less invasive.

The cumulative proportion at the time revealed that half of the files were intact at the instrumentation of the $11^{\text {th }}$ canal in the first group and at the $17^{\text {th }}$ canal in the second one. At the instrumentation of the $14^{\text {th }}$ canal, after the creation of a glide path, all WaveOne files were intact (100\% survival) while all of them from the other group (without a glide path) were broken. The great number of uses can be attributed not only to the creation of a glide path but to the specific reciprocal way of rotation of WaveOne files and their design, as well. It is well documented that the incidence of instrument fractures (in resin blocks and natural teeth) is lower with alternating rotation than with continuous rotation $[13,34,35,40]$. The lifespan of an instrument is directly proportional to the stress accumulated during work in the root canal [5]. The torsional stress is reduced by using reciprocating motion and taper-lock phenomenon is prevented by unsymmetrical repeating of the clockwise and counterclockwise rotations [39]. In combination with initial preflaring, torsional stress is decreased and the area on which the stress is exerted on is shifted (from the tip to the body of the file), further reducing any torsional stress.

In conclusion, within the limitations of this study, NiTi Rotary PathFiles are suitable instruments for safe and easy creation of the glide path before use of NiTi rotary instruments for shaping the canal. The PathFiles System is less technique-sensitive and increases significantly the lifespan and survival rate of WaveOne reciprocating files.

\section{Acknowledgement}

The study is sponsored by the Scientific Council of Medical University, Sofia, Bulgaria.

\section{References}

[1] Alapati SB, et al. Brantley WA, Svec TA, Powers JM, Nusstein JM, Daehn GS. SEM observations of nickel-titanium rotary endodontic instruments that fractured during clinical use. J.Endod 200531 (1): 40-43

[2] Berruti E, Negro AR, Lendini M, Pasqualini D. Influence of manual preflaring and torque on the failure rate of ProTaper rotary instruments. J Endod 2004; 30: 228-30

[3] Berruti E, Paolino DS, Chiandussi G, et al. Root canal anatomy preservation of WaveOne reciprocating files with and without glide path. J Endod 2012; 38: 101-4.

[4] Berutti E, Cantatore G. Rotary instruments in Nickel Titanium. In: Castellucci A. Endodontics Vol. 1. Ed. Il Tridente Florence 2006: 518-547.

[5] Berutti E, Chiandussi G, Gaviglio I, Ibba A: Comparative analysis of torsional and bending stresses in two mathematical models of nickel titanium rotary instruments: ProTaper versus ProFile. J Endodon 2003; 1 (29): 15-19.

[6] Cheung GS, Peng B, Bian Z, Shen Y, Darvell BW. Defects in ProTaper S1 instruments after clinical use: fractographic examination. Int Endod J 200538 (11): 802-809.

[7] Davis RD, Marshall JG, Baumgartner JC. Effect of early coronal flaring on working length change in curved canals using rotary nickel-titanium versus stainless steel instruments. J Endod 2003; 28: 438-42.

[8] Di Fiore PM. A dozen ways to prevent nickel-titanium rotary instrument fracture. J Am Dent Assoc 2007; 138: 196-201. 
[9] Garip Y, Gunday M. The use of computed tomography when comparing nickel-titanium and stainless steel files during preparation of simulated curved canals. Int Endod J 2001; 34: 452-457.

[10] Iqbal MK, Kohli MR, Kim JS. A retrospective clinical study of incidence of root canal instrument separation in an endodontics graduate programme: A PennEndo database study. J Endod 2006; 32: 1048-52.

[11] Martin B, Zelada G, Varela P, et al. Factors influencing the fracture of nickel-titanium rotary instruments. J Endod 2003; 36: 262-6.

[12] Parahos P, Gordon I, Messer HH. Factors influencing defects of rotary nickel-titanium endodontic instruments after clinical use. J Endod 2004; 30: 722-5.

[13] Pedulla E, Grande NM, Plotino G, Gambarini G, Rapisarda E. Influence of continuous or reciprocating motion on cyclic fatigue resistance of 4 different nickel-titanium rotary instruments. J Enodod 2103; 39: 258-261.

[14] Peters OA, Peters CI, Schonenberger K, Barbakow F. ProTaper rotary root canal preparation: assessment of torque and force in relation to canal anatomy. Int Endod J 2003; 36: 93-99.

[15] Peters OA, Peters CI. Cleaning and shaping of the root canal system. In: Hargreaves KM, Cohen S, eds. Cohen's Pathways of the Pulp, $10^{\text {th }}$ ed. St. Louis, MO, Mosby; 2010: 283-348.

[16] Peters OA. Current challenges and concepts in the preparation of root canal systems: a review. J Endod 2004; 30 (6): 559-567.

[17] Pettiette MT, Delano EO, Trope M. Evaluation of success rate of endodontic treatment performed by students with stainless-steel Kfiles and nickel-titanium hand files. J Endod 2001; 27: 124-27.

[18] Pruett JP, Clement DJ, Carnes DL Jr. Cyclic fatigue testing of nickel-titanium endodontic instruments. J Endod 1997; 23: 77-85.

[19] Roland DD, Andelin WE, Browning DF, Hsu G-HR, Torabinejad $\mathrm{M}$. The effect of preflaring on the rates of separation for 0.04 taper nickel titanium rotary instruments. J Endod 2002; 28: 543545.

[20] Ruddle CJ. The ProTaper technique. Endod Topics 2005; 10: 18790.

[21] Sattapan B, Nervo GJ, Palamara JE, Messer HH. Defects in rotary nickel-titanium files after clinical use. J Endod 2000; 26: 161-5.

[22] Sattapan B, Palamara JE, Messer HH. Torque during canal instrumentation using rotary nickel-titanium files. J Endod 2000; 26: $156-60$.

[23] Schäfer E, Florek H. Efficiency of rotary nickel-titanium K3 instruments compared with stainless-steel hand KFlexofile. Part 1. Shaping ability in simulated curved canals. Int Endod J 2003; 36: 199-207.

[24] Schäfer E, Lohmann D. Efficiency of rotary nickel-titanium FlexMaster instruments compared with stainless steel hand $K$ Flexofile: part 1. Shaping ability in simulated curved canals. Int Endod J 2002; 35: 505-13.

[25] Schäfer E, Schlingemann R. Efficiency of rotary nickel-titanium K3 instruments compared with stainless steel hand K-Flexofile, part 2: Cleaning effectiveness and instrumentation results in severely curved root canals of extracted teeth. Int Endod J 2003; 36: 208-17.

[26] Schäfer E, Schulz-Bongert U, Tulus G. Comparison of Hand Stainless Steel and Nickel Titanium Rotary Instrumentation: A Clinical Study. J Endod 2004; 30 (6): 432-435.

[27] Setzer FC, Bombe CP. Influence of combined cyclic fatigue and torsional stress on the fracture point of nickel-titanium rotary instruments. J Endod 2013; 39: 133-137.

[28] Short JA, Morgan LA, Baumgartner JC. A comparison of canal centering ability of four instrumentation techniques. J Endod 1997; 23: 503-7.

[29] Sonntag D, Guntermann A, Kim SK, Stachniss V. Root canal shaping with manual stainless steel files and rotary NiTi files performed by students. Int Endod J, 2003; 36: 246-255.

[30] Suter B, Lussi A, Sequeira P. Probability of removing fractured instruments from root canals. Int Endod J 2005; 38: 112-123.

[31] Taşdemir T, Aydemir H, Inan U, Ünal O. Canal preparation with Hero 642 rotary NiTi instruments compared with stainless steel hand K-file using computed tomography. Int Endod J 2005; 38: 402-408.

[32] Tygesen YA, Steiman R, Ciavarro C. Comparison of diltortion nad separation utilizing ProFile and Pow-R nickel-titanium rotary files. J Endod 2001; 27: 762-4.

[33] Varela Patino P, Biedma B, Rodriguez CL, Cantatore G, Bahillo JC. The Influence of a Manual Glide Path on the Separation Rate of NiTi Rotary Instruments. J Endodon 2005; 31 (2): 114-116.

[34] Varela-Patino P, Ibanez-Parraga A, Rivas-Mundina B, et al. Alternating versus continuous rotation: A comparative study of the effect on instrument life. J Endod 2010; 36: 157-9.

[35] Varela-Patino P, Martin B, Rodrigues NJ, et al. Fracture rate of nickel-titanium instruments using continuous versus alternating rotation. Endodontic practice Today 2008; 2: 193-7.

[36] Weiger R, Brückner M, ElAyouti A, Löst C. Preparation of curved canals with rotary FlexMaster instruments compared to Lightspeed instruments and hand files. Int Endod J 2003; 36: 48390.

[37] Yao JH, Schwartz SA, Beeson TJ. Cyclic fatigue of three types of rotary nickel-titanium files in a dynamic model. J Endod 2006; 32: 55-7.

[38] Yared G. Canal preparation using only one NiTi rotary instrument preliminary observations. Int Endod J 2008; 41: 339-44.

[39] Yared GM, Bou Dagher FE, Machtou P. Influence of rotational speed, torque, and operator's proficiency on ProFile failures. Int Endod J 2001; 34: 47-53.

[40] You SY, Bae KS, Baek SH, et al. Lifespan of one nickel-titanium rotary file with reciprocating motion in curved root canals. J Endod 2010; 36: 1991-94.

[41] Zelada G, Varela P, Martin B, et al. The effect of rotational speed and the curvature of root canals on the breakage of rotary endodontic instruments. J Endod 2002; 28: 540-2. 